\title{
Industrialization in developing countries brings alterations in the life and can lead serious health consequences
}

\author{
Mrs. Sweety \\ (Community Health Nursing, LLRINE, Gulab devi hospital/Baba Farid University Of Health Science, India)
}

\begin{abstract}
Industrialization in developing countries brings alterations in the life and if appropriate safety measures are not adopted it can lead serious health consequences. Occupational environment may affect the health of people in the working area. Occupational accidents are major occupational hazards in the industries. A pre experimental study was conducted on 60 factory workers of Kapsons industries of district Jalandhar. The knowledge and practice of the workers was assessed before and after giving structured teaching programme regarding occupational hazards and its safety measures with structured questionnaire and observational checklist. The result of the study was in pre test $23 \%$ respondent had good, $67 \%$ had average and $10 \%$ had poor knowledge. In post test $12 \%$ respondent had excellent, $58 \%$ had good, $27 \%$ had average and $3 \%$ had poor knowledge. In pre test practices only $10 \%$ respondent had good level. In post test practices $55 \%$ respondent had good level and $45 \%$ had average. In the study knowledge was associated with educational. The study indicates that structured teaching programme had good impact on workers knowledge and practices. The study recommended that special training programme for workers can help to prevent occupational hazards in the factory
\end{abstract}

Key words: knowledge and practice, occupational hazards, safety measures.

\section{Introduction}

Industrialization in developing countries brings alterations in the life of these countries and if industries are not well designed, appropriate safety measures are not adopted can leads serious adverse health consequences. $^{1}$

Occupational environment is the sum total of external conditions which exists in the work place. It may affect the health of people in the working area. The external conditions and influences which may affect the health of workers include physical agents, biological agents, chemical agents, mechanical agents and psychosocial agents. ${ }^{2}$ In an occupational area due to the influence of above mentioned agents a worker may be exposed to five types of hazards, depending upon his/her occupation. They are Physical Hazards, Chemical Hazards, Biological Hazards, Mechanical Hazards and Psychosocial Hazards. Physical hazards include Noise, Vibration, Lighting, Ionizing, Radiation, Electricity Asphyxiation, hypothermia and hyperthermia. Chemical hazards include Acids, Bases, Heavy metals and Asbestos. Biological hazards include Bacteria, Virus, Fungi and Mold. Mechanical hazards include impact force, ,Collisions ,Falls from height, Struck by objects, Confined space, Slips and trips, Falling on a pointed object, Compressed air/high pressure fluids such as cutting fluid, Entanglement, Equipment -related injury, like Crushing, Cutting, Friction and abrasion, shearing, stabbing and puncture. Psychosocial issues include Work-related stress, Violence, Exposure to unhealthy elements like tobacco, uncontrolled alcohol, and musculoskeletal disorder. ${ }^{3}$

Occupational accidents are also major occupational hazards in the industries. There are various factors responsible for accidents in industries, these are classified as human factors and environmental factors .Human factors included physical, physiological and psychological factors. The physical factors include impaired vision and sight. The physiological factors are age, gender, fatigue etc. The psychological factors include their level of confidence, concentration, emotional stress, dissatisfaction etc. Psychological factor have been more responsible for accidents than physiological factors. ${ }^{2}$

Equipment-related injuries are major source of difficulty faced by workers at the factories. The nature of these problems will vary by work sector, age, gender, and other factors, but hundreds and thousands of individuals suffer from workplace-related injuries each year. Many of the injured go on to have a permanent disability that may threaten their livelihoods ${ }^{4}$

As the term "occupational safety and health" implies that there are two aspects to this field. One is the area of safety, which seeks to make workplaces safe for workers so that they do not suffer injuries. Second is occupational health, the main aim of occupational health is to prevent the occurrence of illnesses among workers because of exposures at their place of work. The occupational diseases and exposure to hazards can be prevented by various measures like pre- placement examination, periodic examination, various medical and health care services, notification, supervision of working environment, health education and counseling etc. ${ }^{2}$ 
Metals are ubiquitous. They are an important and essential part of our daily life. There are more benefits. They have contributed immensely to rapid advances in health care, information technology, telecommunications, construction, and other sectors of industry. Additionally, metals such as iron, copper, zinc, and molybdenum are essential for innumerable biological processes and enzymatic reactions that occur in the human body. But their presence in our environment can cause health risks and hazards like acute toxicity and carcinogenesis. The public health professionals, safety staff, and policy makers develop policies and implement safety programs which help to protect the health of workers and other members of society must become aware with the hazards. Overwhelming evidence shows that hazardous work, working conditions, and environment fail to maintain homeostasis resulting in death or severe disability. Up to the 1980s, government did not pay major attention to occupational health in developing countries, including India. The Bhopal Gas Tragedy, in 1984, was the turning point in the history of industrial health and safety in India. It was time for the government to think deeply and review the existing legislative measures, for the upliftment of the occupational health situation in India. However, all the services remain grossly underutilized because of either inadequate strategies, policies, or the lack of a proper monitoring mechanism for occupational workers. ${ }^{5}$

Occupational hazards contribute to the premature death of millions of people worldwide and result in the ill health or disablement of hundreds of millions more each year. The burden of disease from selected occupational risk factors amounts to $1.5 \%$ risks of the global burden in terms of DALY. The World Health Report 2002 places occupational risks as the $10^{\text {th }}$ leading cause of morbidity and mortality. Almost 22.5 million DALY and 699,000 deaths are attributable to this risk factors. ${ }^{6}$

South East Asia Region countries have witnessed major occupational health problems highlighted by the Bhopal disaster in India and the Kader Toy Factory fire in Thailand. Most of the countries in the Region are in the process of rapid economical development, a process that potentially amplifies the pre-existing traditional risks and introduces new occupational risks in the region. Thus, occupational health is of major concern in the South East Asia Region of WHO with a work force of about 500 million persons. Work-related deaths, diseases and injuries remain at unacceptably high levels and result in an economic loss amounting to about 4-5\% GDP. ${ }^{6}$

Occupational Health Services comprise comprehensive health care services which are provided not only to workers but also to their family members. The occupational health services includes primary, secondary and tertiary level services to promote \& protect health, prevent and control diseases and disabilities and rehabilitate. $^{2}$

Occupational health nurse has her primary responsibility towards workers to promote, protect and preserve their health. She is also responsible towards her employer to protect the company from adverse effect of work processes and hazardous substances on workers. The various activities of occupational health nurse are Pre placement examination, periodic examination, health education and counseling of workers about various health issues, interaction with the management to initiate health activity and implementing immunization and safety measure, investigation of health hazards, diseases and carrying treatment and rehabilitative measures .

The education about occupational hazards and safety measures are the ideal means of preventing occupational diseases and injuries at work place. ${ }^{7}$ 


\section{Research Methodology}

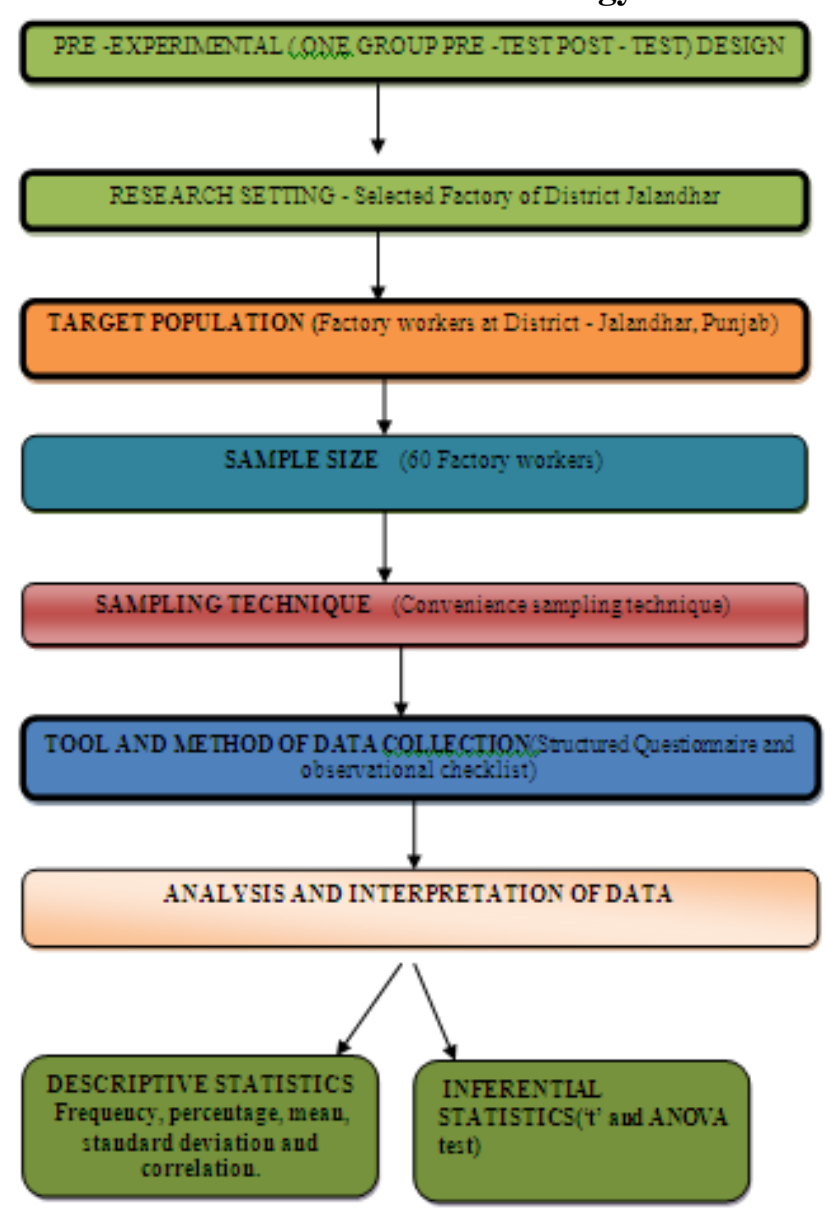

\section{Results}

Table 1: Comparison of pre and post test mean knowledge score among factory workers regarding occupational hazards and its safety measures

\begin{tabular}{llllll}
\hline Mean knowledge score & & & & \\
\hline & $\mathbf{N}$ & Mean & S. D & V & 't' \\
Pre test & 60 & 10.52 & 2.98 & 8.88 & $5.66^{*}$ \\
Post test & 60 & 14.20 & 3.98 & 15.08 & \\
Difference & & -4.32 & & & \\
\hline score 22 & & & *Significant at P<0.05 level
\end{tabular}

Maximum score 22

*Significant at $\mathrm{P}<0.05$ level

Minimum score 0

Table1 depicts that the post test mean knowledge score (14.2) was higher than the pretest mean knowledge score (10.52) and it is statically significant at $\mathrm{P}<0.05$ level. ' $\mathrm{t}$ ' value is 5.66 which is more than 1.960 at $5 \%$ and 2.58 at $1 \%$ level of significance. Hence $\mathrm{H}_{1}$ is accepted and $\mathrm{H}_{01}$ is rejected, the knowledge of factory workers has increased with structured teaching programme and it has good impact on knowledge among factory workers regarding occupational hazards and its safety measures.

Table 2: Comparison of pre and post test mean practices score among factory workers regarding occupational hazards and its safety measures. $\mathrm{N}=60$

\begin{tabular}{llllll}
\hline Mean practice score & & & & & \\
& $\mathbf{n}$ & $\mathbf{M}$ & S. D & V & 't' \\
& & & & 1.976 & $8.4^{*}$ \\
Pre test & 60 & 7.41 & 1.41 & 1.816 & \\
Post test & 60 & 9.51 & 1.34 & & \\
Difference & & -2.1 & & \\
\hline
\end{tabular}

Maximum score 13

*Significant at $\mathrm{P}<0.05$ level

Minimum score 0 
Table 2 reveals that the post test mean practice score (9.51) was higher than the pretest mean practice score (7.41) and it is statically significant at $\mathrm{P}<0.05$ level. ' $t$ ' value is 8.4 which is more than 1.96 at $5 \%, 2.58$ at $1 \%$ level of significance. Hence $\mathrm{H}_{02}$ is accepted and $\mathrm{H}_{0}$ is rejected it shows that practices has increased with structured teaching programme and it has good impact on practices among factory workers regarding occupational hazards and its safety measures.

Table- 3: Association of Pre and Post test mean knowledge score among factory workers regarding occupational hazards and its safety measures according to Education

$\mathbf{N}=\mathbf{6 0}$

\begin{tabular}{|c|c|c|c|c|c|c|c|c|c|c|c|}
\hline \multicolumn{12}{|c|}{ Mean knowledge score } \\
\hline & & test & & & & Post t & & & & & \\
\hline $\begin{array}{l}\text { Educational } \\
\text { status }\end{array}$ & $\mathbf{n}$ & $\mathbf{M}$ & SD & $\mathbf{V}$ & df & $\mathbf{F}$ & M & SD & $\mathbf{V}$ & df & $\mathbf{F}$ \\
\hline Primary & 20 & 8.8 & 2.48 & 6.16 & 3,56 & $9.02 *$ & 12.4 & 3.65 & 13.34 & 3,56 & $9.24 *$ \\
\hline Secondary & 19 & 10.11 & 2.6 & 6.76 & & & 15.1 & 3.12 & 9.77 & & \\
\hline High secondary & 12 & 10.05 & 3.67 & 13.42 & & & 15.0 & 4.93 & 24.33 & & \\
\hline Graduate & 09 & 11.56 & 3.23 & 10.47 & & & 17.37 & 1.49 & 2.22 & & \\
\hline
\end{tabular}

Maximum score 22

Minimum score 0

NS Non-Significant

* Significant at $\mathrm{p}<0.05$ level

Table -3 depicts that pretest mean knowledge score was highest (11.56) in the participants who were graduate and above, followed by score (10.11)in secondary educated, score (10.05) in the higher secondary educated and score (8.8) in the primary educated person. In the posttest maximum of participants who were educated graduate and above had mean score 17.37 followed by the participants educated up to secondary with mean score 15.01then participants who were educated upto higher secondary had mean score 15.0 and who were primary educated with least mean score 12.4. The difference between the pretest and posttest mean knowledge score was significant, since calculated value of $\mathrm{F}$ was more than the tabulated value, so $\mathrm{H}_{3}$ is accepted, hence it can be concluded that education had impact on knowledge of workers regarding occupational hazards and its safety measures

\section{Major Findings}

The finding of the study suggest that that maximum (67\%) of worker had average knowledge regarding occupational hazards and its safety measures, $23 \%$ of them had good knowledge, $10 \%$ of them had poor knowledge in the pre test .In post test maximum (58\%) workers had good knowledge ,27\% of them had average knowledge, $12 \%$ had excellent knowledge and only $3 \%$ had poor knowledge

The finding of the study suggest that in pre test $90 \%$ of workers had average practice score and only $10 \%$ of them had good practice score regarding occupational hazards and its safety measures. In post test 55\% of workers had good practice score and $45 \%$ of them had average practice score

This statistical statements show that the difference between the pretest and post test mean knowledge score was significant only in educational status.

\section{Discussion}

The study was conducted on 60 factory workers in Kapsons industries of District Jalandhar, Punjab.

First objective of the study was to assess the knowledge regarding occupational hazards and its safety measures among factory workers.

The finding of the study suggest that maximum (67\%) of worker had average knowledge regarding occupational hazards and its safety measures, $23 \%$ of them had good knowledge, $10 \%$ of them had poor knowledge in the pre test .In post test maximum (58\%) workers had good knowledge, $27 \%$ of them had average knowledge, $12 \%$ had excellent knowledge and only $3 \%$ had poor knowledge. So knowledge score has gone up. There was 35\% knowledge increase in the range of score 13-18 and further there were $12 \%$ persons falls in range of score $18-22$.In pretest there was no one in the range of score 18-22 and 31\% workers shifted from average to good knowledge range. These figures showed that after structure teaching programme the knowledge regarding occupational hazards and its safety measures of factory workers has increased.

The finding of the study was supporting by Sokas RK, Emile J,Nickels L, Gao W, Gittleman JL conducted A study to assess effectiveness of hazard awareness training in the construction building trades (Chicago, USA,Nov 2011) found that out of 175 workers $92(53 \%)$ respondents completed a survey which documented significant increase in knowledge related fall safety and electrical safety. ${ }^{8}$

The second objective of the study was to assess the practices regarding occupational hazards and its safety measures among factory workers. 
The finding of the study suggest that in pre test $90 \%$ of workers had average practice score and only $10 \%$ of them had good practice score regarding occupational hazards and its safety measures. In post test 55\% of workers had good practice score and $45 \%$ of them had average practice score. Practices has increased because it is found that from $45 \%$ person in the range of 5-9 score (in pretest) is decreases and shifted from average to good practice range. This showed that with structured teaching programme the practice of safety measures has increased.

The findings of the study supported by Parker DL, Brosseau LM, Samant Y, Xi M,Pan W, Haugan D et al conducted study on A randomized, controlled intervention of machine guarding and related safety programs in small metal-fabrication businesses in USA(2009). The researcher evaluated 40 metal fabrication businesses at baseline and 37(93\%) one year later which revealed that more than $40 \%$ of devices required for adequate guarding and $35 \%$ of required safety programme and practice. Both measures improved significantly during the course of the intervention. The results showed that Machine-guarding practices and programs improved by up to $13 \%$ and safety audit scores by up to $23 \%$. The researcher was recommended that Simple and easy-to-use assessment tools allowed businesses to significantly improve their safety practices, and safety committees facilitated this process. ${ }^{9}$

The third objective of the study was to find out the association of knowledge and practices with selected socio demographic variables.

The findings of the study had shown the association of knowledge and practices with selected socio demographic variables including age, gender, education, work experience, income, source of information.

This statistical statements show that the difference between the pretest and posttest mean knowledge score was significant only in educational status. Other socio demographic variables had no significant association with knowledge, but practice had no association with any sociodemographic variable In contrast a study by Hafiz 0. Al me. Knowledge And Practices Related To Occupational Hazards Among Cement Workers In United Arab Emirates (2010) reported that The majority 114 (74.5\%) of the workers knew that exposure to the dust was a serious hazard to their health, but only $52.9 \%$ of the workers knew the hazards other than the dust that were associated with their work. All the workers mentioned that they had been provided with masks to protect them from dust; however, only $28.8 \%$ of them claimed that they used the masks all the time during working hours. . The variables years of education, being informed about the hazards associated with the worker's job, and attending a training course about occupational health and safety were found to have a significant influence on the workers' knowledge about the occupational hazards and on their use of the personal protective equipment at work. The study concluded that despite the relatively high knowledge of the cement factory workers about the adverse health effects of exposure to dust, the use of respiratory protective equipment was poor. A program to promote safety education and the use of personal protective equipment among cement factory workers is recommended. ${ }^{1}$

\section{Conclusion}

The finding of the study had shown that in pretest the10\% of participants had good practice score regarding occupational hazards and its safety measures. So, there was need to improve the knowledge and practices of participants by organizing the structure teaching programme because their knowledge and practices was important to prevent the occupational hazards. It was found that from all the variables like age, gender, educational status, work experience, income and source of information only educational status had association with knowledge but there was no association of any variable with practice.

\section{References}

[1]. Hafiz 0. Al med, Knowledge And Practices Related To Occupational Hazards Among Cement WorkersIn UnitedArab Emirates:j.Egypt, Public Health Association 2010 vol.85 ;3-4,

[2]. Gulani K.K ,Community health nursing principles and Practices. $1^{\text {st }}$ ed ,Delhi: Kumar publishers;2008 : $327-330$.

[3]. Rena Metha Occupational hazards caused te operations.en.wikipedia.org/.../Occupational_Safety_and_Health_Administration.

[4]. L.Frank. Occupational health and safety .www.answer .com/main /what_content.jsp.

[5]. Asish Kumar Mandal, Strategies and policies deteriorate occupational health situation in India: A review based on social determinant framework, Indian J Occup Environ Med. 2009 December; 13(3): 113-120.

[6]. www.searo.who.int/en/Section23/Section1214/Section1223_4900.htm

[7]. Joshi sonopant,Preventing occupational health hazards in mechanical industries.2009;vol.5(1):24-26.

[8]. Sokas RK, Emile J, Nickels L, Gao W, Gittleman JL,An intervention effectiveness study of hazard awareness training in the construction building trades, Science Total Environment. Feb 20121;416:121-6. Epub 2011 Nov 30.

[9]. $\quad \underline{\text { Parker DL }}, \underline{\text { Brosseau LM }}, \underline{\text { Samant Y }}, \underline{\mathrm{Xi} \mathrm{M}}, \underline{\text { Pan W}}, \underline{\text { Haugan D }}$ et al: A randomized, controlled intervention of machine guarding and related safety programs in small metal-fabrication businesses, public health report, Jul-Aug 2009 ;124 Suppl 1:90-100. 